\title{
Motor responses of the oesophagus to intraluminal distension in normal subjects and patients with oesophageal clearance disorders
}

\author{
G P N KENDALL, D G THOMPSON, S J DAY, AND N GARVIE \\ From the Department of Medical Research, St Mark's Hospital, London and Departments of Gastroenterology, \\ Biometry and Nuclear Medicine. The London Hospital, London
}

SUMMARY Oesophageal motor responses to intraluminal distension were studied manometrically in 16 healthy volunteers and in nine patients with disordered swallowing, who had prolonged oesophageal clearance without structural abnormality. In the normal subjects distension was associated with an increased number of secondary contractions above the balloon, decrease of all contractile activity below the balloon and was accompanied by an aborally propulsive force which occurred independently of the perception of discomfort. Cholinergic blockade abolished the proximal distension induced contractile response, but did not affect primary peristalsis. Despite normal sensory thresholds, proximal excitatory responses to distension were absent in six and distal inhibition was absent in seven patients. These results show that the normal human oesophagus responds to distension with a proximal enhancement of propulsive motor activity, mediated through a cholinergic pathway. This may be defective in some patients with disordered oesophageal transit. Investigation of the motor responses to intraluminal distension may thus be a useful adjunct to standard manometry for studying patients with suspected oesophageal clearance dysfunction and might allow identification of disordered enteric nervous control.

Oesophageal transport occurs through two peristaltic mechanisms.' Primary, or swallow initiated, peristalsis which is centrally mediated originates in the pharynx and progresses aborally to the stomach. If food remains in the oesophagus distending the lumen then local neural reflexes induce secondary, or nonswallow initiated, peristaltic activity to clear it.' Supine radionuclide oesophageal transit has been advocated as a sensitive screening method for detecting oesophageal motility disorders. ' In some cases, however, no structural or manometric cause for delayed transit can be found and some people consider these cases to be false positive results. ${ }^{+}$ Radionuclide transit studies,, 3 measure the time taken for an ingested isotopically labelled bolus to traverse the oesophagus and provide information on the efficiency of oesophageal clearance. The usual

Address for correspondence: Dr D G Thompson. Department of Medicine, Hope Hospital, Salford M6 8HD).

Received for publication 11 July 1986. procedure involves one swallow at the start of the test so that speed of clearance is a function of the efficiency of one primary peristaltic contraction and any subsequent secondary activity. Standard oesophageal manometry is useful for defining abnormalities of primary peristalsis, but secondary peristalsis, in contrast, is not usually demonstrated and transit of intraluminal contents is not evaluated. Secondary peristalsis has been studied experimentally and can be induced by intraluminal balloon distension, ${ }^{(-2)}$ but it has not previously been investigated in patients with swallowing difficulties.

We hypothesised that patients with delayed oesophageal clearance but apparently normal manometry might have abnormal secondary peristaltic activity. We therefore performed the series of studies described below with the aim of defining the normal responses of the human oesophagus to localised distension and comparing this information with that obtained from patients with unexplained oesophageal clearance disorders. 
Table Details of the patients symptoms and their investigations

\begin{tabular}{|c|c|c|c|c|c|c|c|c|}
\hline $\begin{array}{l}\text { C'ase' } \\
\text { no }\end{array}$ & Age' & Sex & History & $\begin{array}{l}\text { Bariumswallow } \\
\text { report }\end{array}$ & SROT & Standard manometry & $\begin{array}{l}\text { Distension } \\
\text { proximal } \\
\text { excitation }\end{array}$ & $\begin{array}{l}\text { Response } \\
\text { distal } \\
\text { inhibition }\end{array}$ \\
\hline 1 & 41 & M & $\begin{array}{l}17 \text { yreffortless regurgitation } \\
\text { of food. }\end{array}$ & Normal & $4.3 \mathrm{sec}$ & $\begin{array}{l}\text { Normal peristalsis, LOS } 10 \\
\text { mmllg. Normal relaxation }\end{array}$ & Absent & Absent \\
\hline 2 & 43 & $\mathrm{~F}$ & $\begin{array}{l}3 \text { yr food sticking on } \\
\text { swallowing, regurgitation, } \\
\text { retrosternal pain with food }\end{array}$ & Normal & $>60) \sec$ & $\begin{array}{l}\text { Normal peristalsis. LOS } 6 \\
\text { mmHG. Normal relaxation }\end{array}$ & Absent & Absent \\
\hline 3 & 67 & $\mathbf{F}$ & $\begin{array}{l}3 \text { yr food sticking on } \\
\text { swallowing }\end{array}$ & $\begin{array}{l}\text { Tapered lower } \\
\text { ocsophagus }\end{array}$ & $22 \mathrm{sec}$ & $\begin{array}{l}\text { Normal peristalsis. LOS } 12 \cdot 5 \\
\text { mmllg. No relaxation }\end{array}$ & Absent & Absent \\
\hline 4 & 55 & $\mathrm{~F}$ & $\begin{array}{l}4 \text { yr food sticking on } \\
\text { swallowing, retrosternal } \\
\text { pain with food }\end{array}$ & $\begin{array}{l}\text { Hold up at lower } \\
\text { ocsophagus }\end{array}$ & $>6() \mathrm{sec}$ & $\begin{array}{l}\text { Low amplitude peristalsis. } \\
\text { LOS } 12.5 \mathrm{~mm} \mathrm{Ig} \text {. No } \\
\text { relaxation }\end{array}$ & Absent & Absent \\
\hline 5 & 39 & $\mathbf{M}$ & $\begin{array}{l}1 \text { yr retrosternal pain and } \\
\text { dysphagia with food }\end{array}$ & $\begin{array}{l}\text { Hold up at lower } \\
\text { ocsophagus }\end{array}$ & $23 \mathrm{sec}$ & $\begin{array}{c}\text { Multipeaked peristalsis, LOS } \\
12.5 \mathrm{~mm} / \mathrm{lg} \text {. No relaxation }\end{array}$ & Present & Present \\
\hline 6 & 79 & $\mathrm{~F}$ & $\begin{array}{l}\text { I yr choking and retrosternal } \\
\text { pain with food }\end{array}$ & $\begin{array}{l}\text { Poorly contractile } \\
\text { ocsophagus, hold } \\
\text { up at lower } \\
\text { ocsophagus }\end{array}$ & $20 \sec$ & $\begin{array}{l}\text { Low amplitude peristalsis, } \\
\text { LOS } 27.5 \mathrm{~mm} H \mathrm{H} \text {. Normal } \\
\text { relaxation }\end{array}$ & Absent & Absent \\
\hline 7 & 29 & $\mathbf{F}$ & $\begin{array}{l}\text { 10) yr retrosternal pain on } \\
\text { cating }\end{array}$ & - & $25 \mathrm{sec}$ & $\begin{array}{l}\text { Normal peristalsis, } \operatorname{LOS} 12 \cdot 5 \\
\mathrm{mmHg} \text {. Normal relaxation }\end{array}$ & Present & Absent \\
\hline 8 & 38 & M & $\begin{array}{l}2 \text { yr retrosternal pain with } \\
\text { food }\end{array}$ & $\begin{array}{l}\text { Tertiary peristaltic } \\
\text { waves }\end{array}$ & $17 \mathrm{sec}$ & $\begin{array}{l}\text { Multipeaked peristalsis. No } \\
\text { LOS demonstrated }\end{array}$ & Absent & Absent \\
\hline 9 & 41 & $\mathbf{M}$ & $\begin{array}{l}1 \text { yr chest pain. regurgitation } \\
\text { with food }\end{array}$ & $\begin{array}{l}\text { Tertiary peristaltic } \\
\text { waves }\end{array}$ & $16 \mathrm{sec}$ & $\begin{array}{l}\text { Multipeaked peristalsis. No } \\
\text { LOS demonstrated }\end{array}$ & Present & Present \\
\hline
\end{tabular}

SROT $=$ supine radionuclide oesophageal transit LOS = lower oesophageal sphincter .

\section{Methods}

SUBJECTS

The study protocols were approved by the London Hospital Ethics Committee. Sixteen healthy adult volunteers (age 19-37), without history of gastrointestinal disorder, and nine patients were studied. The patients comprised all those referred to the gastroenterology unit for oesophageal manometry, over a period of 12 months, with a history of swallowing difficulty that included regurgitation, dysphagia, odynophagia and aspiration (Table). Patients with a dilated oesophagus, endoscopic evidence of oesophagitis or a structural disorder of the oesophagus were excluded from the study and none had obvious evidence of achalasia. All participants gave their informed consent before manometric examination.

OESOPHAGEAI, TRANSIT STUDIES

Supine oesophageal transit was measured according

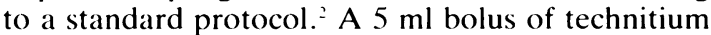
$99 \mathrm{~m}$ sulphur colloid $(150 \mu \mathrm{Ci}, 5.55 \mathrm{MBq})$ was placed in the mouth and the patient was asked to swallow once. Gamma emmissions were counted, over the thorax, for the next 60 seconds using a wide field of view gamma camera (Siemens 37 ZLC) and the data were analysed by computer. From previous validation studies, transit was considered to be abnormally prolonged if the time taken for the level of gamma emmission over the thorax to fall below $10 \%$ of its original activity was greater than 10 seconds.

OESOPHAGEAL. MANOMETRY

Intraluminal oesophageal pressure activity was measured using a standard multilumen perfused tube system." The tube was constructed from 12 radiolucent polyvinyl chloride capillary tubes (internal diameter (ID) $0.63 \mathrm{~mm}$, external diameter (ED) 1.4 $\mathrm{mm}$ ) bonded around a central radio-opaque PVC tube (ID $1.5 \mathrm{~mm}$, ED $2.5 \mathrm{~mm}$ ). A balloon, constructed from a $5 \mathrm{~cm}$ length of condom rubber, was attached $15 \mathrm{~cm}$ from the distal end and was inflated with water through another PVC tube (ID $1 \mathrm{~mm}, \mathrm{ED}$ $1.6 \mathrm{~mm}$ ) (Fig. 1). Each channel was perfused with distilled water, at $0.4 \mathrm{ml}$ per minute, through a pneumohydraulic perfusion pump which gave a pressure response of $100 \mathrm{mmHg} / \mathrm{sec}$ on occlusion of the most distal port. Intraluminal pressure changes were detected, proximal and distal to the balloon, using strain gauge transducers (Gaeltec S8b, Skye, Scotland) attached to the proximal end of each perfused lumen, and were recorded on a multichannel chart recorder (Watanabe Linear Corder mark VII, Tokyo, Japan) at a paper speed of 10() $\mathrm{mm} / \mathrm{min}$.

Swallowing was detected via the most proximal channel of the assembly, which was sited in the lower oropharynx, thus enabling primary and secondary motor activity to be distinguished. 


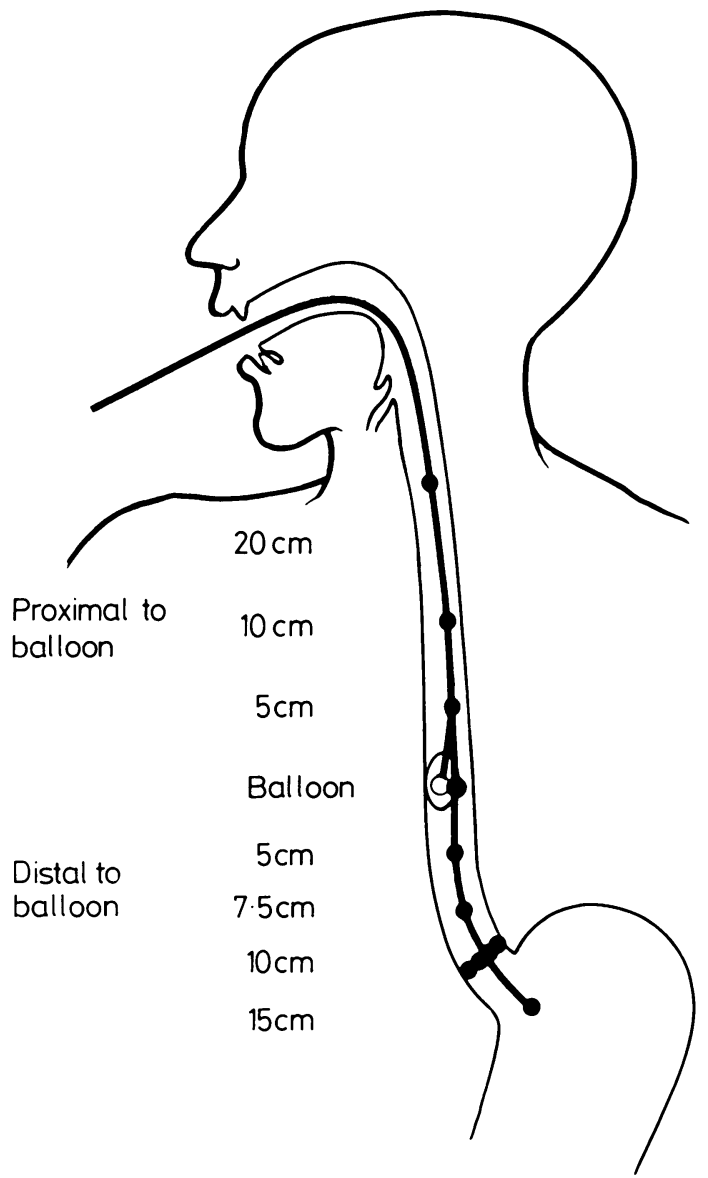

Fig. 1 Position of the multilumen oesophageal tube during the study and the positions of the perfusion ports and the balloon. The construction of the tube ensured that channel 1 was positioned above the upper oesophageal sphincter to indicate swallowing activity. Channel 4 was sited at the mid point of the balloon but on the opposite side of the tube. Channel 8 was sited in the stomach, identified by a positive pressure rise with inspiration. This ensured placement of the balloon 10-15 cm above the diaphragm in all studies.

EXPERIMENTAL PROCEDURE

All studies were carried out the morning after an overnight fast. After swallowing the tube the subjects and patients underwent a standard oesophageal manometric study: 'to identify the lower oesophageal sphincter using a step-wise pull through technique, document its response to swallowing, and to study oesophageal peristaltic activity after 10 dry and five wet swallows each done at 30 second intervals.

DISTENSION STUDIES

After the standard manometric study the position of the tube was readjusted so that the most distal port lay just below the diaphragm, identified by positive inspiratory pressure changes. This manoeuvre ensured that the balloon was consistently positioned $10-15 \mathrm{~cm}$ above the diaphragm in all studies. Thirteen of the normal subjects and all the patients were studied over three consecutive five minute periods. Control periods of recording, without balloon distension, were done before and after a test period during which the balloon was slowly distended with water until retrosternal discomfort was just occurred. Persistence of balloon inflation throughout the study period was confirmed by complete recovery of the water instilled into the balloon, at the end of the procedure. Throughout the study the tube was held in position by the observer, at the angle of the mouth, to prevent tube displacement and to detect the presence of any traction forces applied to the tube.

Pilot studies indicated that balloon distension caused an increase in the volume of salivation and swallowing frequency. As swallowing activity may inhibit the generation of spontaneous oesophageal contractions,? all individuals were asked to restrict the frequency of swallowing during both the test and control periods and to help control swallowing frequency saliva was continuously aspirated from the mouth during the test period.

Six of the 13 subjects underwent a repeat study after an intravenous injection of the cholinergic antagonist (Hyoscine Butylbromide, 20 mg). This was administered at the beginning of balloon distension.

Three additional subjects were studied during a period of subthreshold oesophageal distension. This was achieved by inflating the balloon until retrosternal discomfort was just felt, and then removing half the volume instilled into the balloon for the study period.

\section{DATA ANALYSIS}

Standard oesophageal manometry

The oesophageal motility recordings were examined by inspection and measurements of the amplitude and duration of intraluminal pressure changes were made manually.

\section{Distension studies}

The number of contractions in each channel were counted during both the control and test periods and divided into those related to swallowing (primary) and those unrelated to swallowing (secondary). Comparison of the number of primary and secondary contractions was then made between the two control periods and between the pre-inflation period and the test period. Initial inspection of these data indicated they were positively skewed, a square root transfor- 
mation was therefore performed, before calculating means and standard deviations, in order to render their distribution more normal. The mean (and confidence limits) results quoted in the text are the retransformed values calculated from the square rooted data. To assess the effect of distension on the propagation of swallowing activity, the ratio of primary contractions below and above the balloon was calculated using the channels $5 \mathrm{~cm}$ distal and $5 \mathrm{~cm}$ proximal to the balloon during both the control and test periods. These data appeared normally distributed and thus required no transformation. In all cases statistical comparison was performed using a paired $t$ test $^{12}$ to determine the probability that the observed differences could have occurred by chance.

\section{Results}

NORMAL SUBJECTS

The volunteers all had a normal standard manometric examination.

\section{Control period}

During the control period (Fig. 2) normal primary peristaltic activity was seen together with a few spontaneously occurring secondary contractions. There was no significant difference in the frequency of either primary or secondary contractile activity during the predistension and postdistension periods (Fig. 3).

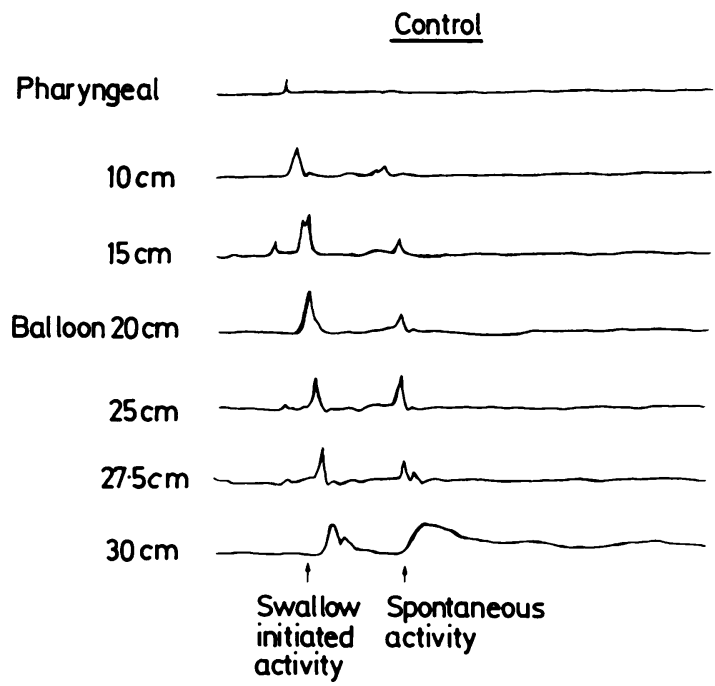

Balloon distension

Balloon distension induced retrosternal discomfort described in similar terms by all 13 subjects (median volume of water instilled $13 \mathrm{ml}$, range $6-30 \mathrm{ml}$; balloon diameter $0.8-3.8 \mathrm{~cm}$ ), and was accompanied by an alteration in the pattern of oesophageal motor activity. This alteration always preceded the perception of the retrosternal discomfort. A marked increase in the number of secondary contractions occurred above the balloon (Figs. 2, 3), the mean (confidence limits) number changing from $2 \cdot()(0 \cdot 9-$ 3.7) secondary contractions $/ 5$ minutes during the predistension period to $18 \cdot 1(12 \cdot 1-25 \cdot 1)$ during the distension period $(\mathrm{p}<0.001)$. Primary peristaltic activity started and propagated normally above the balloon during both the test and control periods (Fig. 3 ). During distension, however, the number of primary contractions traversing the balloon was markedly reduced, the ratio of contractions either side of the balloon (distal/proximal) changing from $1 \pm 0.18$ (mean \pm confidence limits) for the predistension period, to $0 \cdot 38 \pm 0 \cdot 18$ for the distension period, $(p<0.001)$. These changes in motor activity were associated with the development of a variable but persistent aborally directed force on the tube, which was detected manually by the observer and had to be resisted by traction to prevent tube displacement.

On balloon deflation the pattern of motor activity rapidly returned to normal; no specific pattern of activity was related to deflațion.

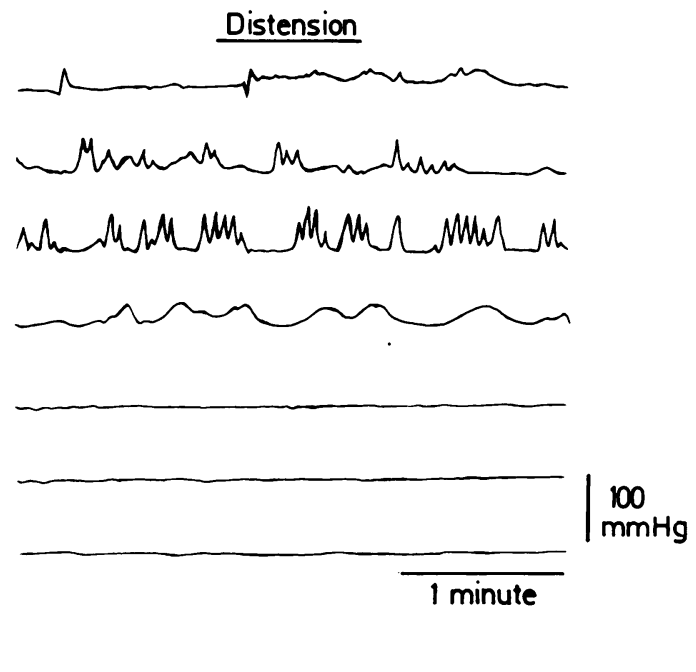

Fig. 2 Oesophageal contractile activity during the predistension (left) and the distension (right) periods in a normal subject. During the predistension pertod normal primary peristalsis is seen together with one secondary contraction. In the distension period there is an increase in secondary contractile activity above the balloon while the propagation of contractions across and below the balloon is reduced. 


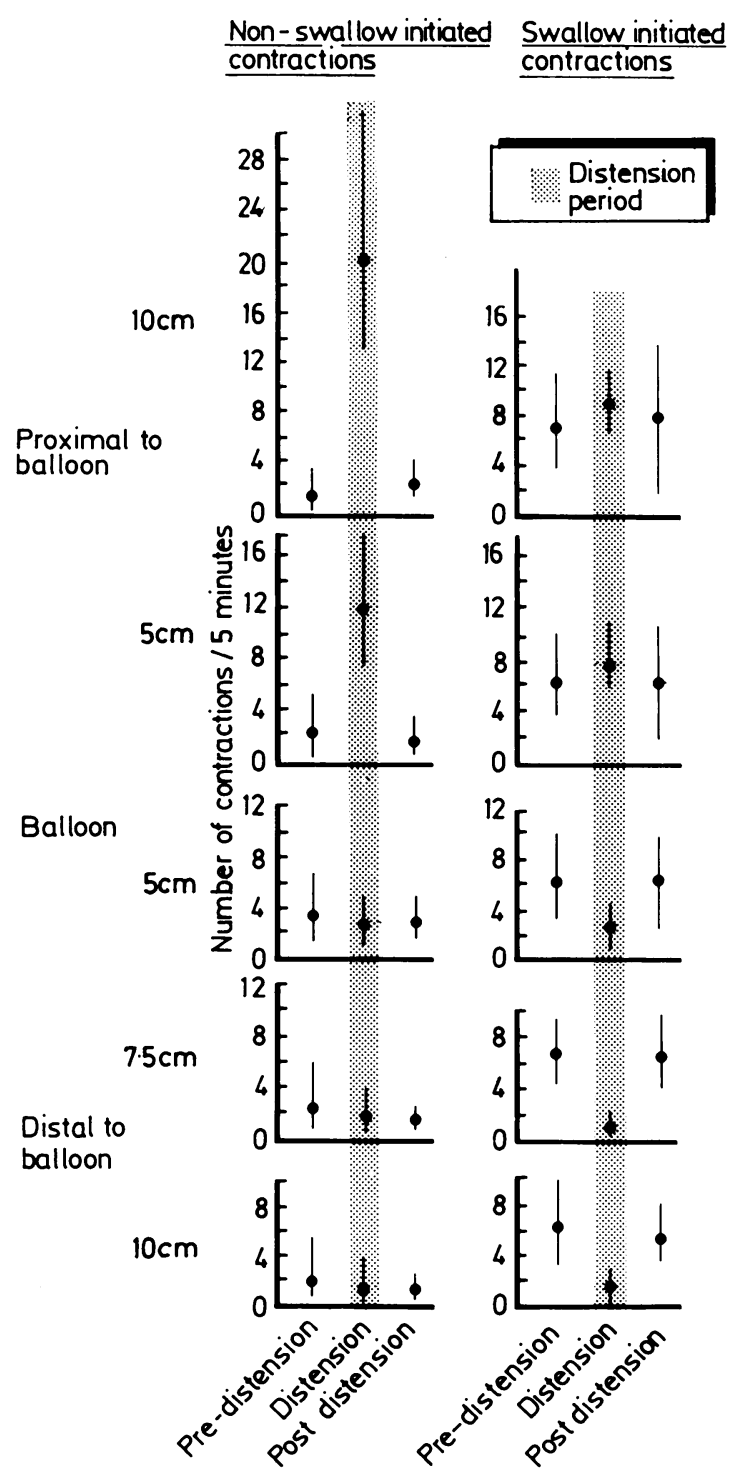

Fig. 3 Frequency of both secondary (left) and primary (right) contractile activity during the predistension, distension and postdistension periods for all the channels proximal and distal to the balloon. No difference is seen between the pre-and postdistension control periods. During distension, however, there is a consistent increase in secondary contractions above the balloon and a reduction in primary peristaltic activity below it.

\section{Subthreshold distension studies}

In the three individuals in whom the balloon was distended without retrosternal discomfort (volume of balloon inflation 3,5 , and $7 \mathrm{ml}$ ), the proximal stimulation of secondary contractile activity was still observed. On these occasions, however, primary peristalsis traversed the balloon and migrated through the distal oesophagus suggesting that distal inhibition required a greater distension threshold than proximal stimulation.

\section{Cholinergic blockade studies}

Administration of hyoscine butylbromide $(20 \mathrm{mg})$ during balloon distension did not alter the sensation of retrosternal discomfort and had no effect on either the initiation or propagation of the primary peristalsis proximal to the balloon. In contrast the distension induced increase in secondary contractile activity was virtually abolished, within one minute of drug injection; the mean number of contractions changing from $22 \cdot 1(11 \cdot 3-36 \cdot 5)$ per five minutes for the distension period without cholinergic blockade to $2.9(0 \cdot 2-8 \cdot 8)$ during cholinergic blockage $(p<0 \cdot 01)$. The persistant aborally directed force on the tube was also abolished.

\section{PATIENT STUDIES}

Details of the symptoms and investigations carried out on the patients are shown in the Table. All suffered from chronic difficulty in swallowing and had delayed isotope transit, but normal oesophageal endoscopy. Barium swallow study suggested a failure of lower oesophageal sphincter relaxation in four patients (case numbers 3-6) although oesophageal diameter appeared normal. On manometry three of the patients (case numbers 3-5) showed abnormal lower oesophageal sphincter responses, with absent relaxation on swallowing, suggesting early achalasia. Abnormalities of primary peristalsis were present in five people; three (case numbers 5, 8, and 9) had multipeaked waves consistent with a diagnosis of diffuse oesophageal spasm, ${ }^{13}$ the others (case numbers 4 and 6) had low amplitude peristalsis. In the three remaining cases (case numbers 1,2 , and 7) no abnormality was detected on either standard manometry or other investigations.

Balloon inflation caused retrosternal discomfort in all the patients at similar volumes to those used in the normal subjects (Median volume of water instilled 15 $\mathrm{ml}$, range $4-30 \mathrm{ml}$ ), indicating similar distension thresholds. As with the normal subjects neither the frequency of swallowing nor its propagation proximal to the balloon was altered during distension. In contrast with the normal subjects, however, six of the nine patients (case numbers $1-4,6$, and 8 ) failed to show an increase in proximal secondary contractile activity (Figs $4,5,6$ ), the mean number of secondary peristaltic contractions proximal to the balloon being $0 \cdot 2(0-1)$ for the predistension period and $0 \cdot 4(0-1 \cdot 6)$ for the distension period $(p>0 \cdot(05)$. Furthermore all primary peristaltic contractions propagated across 
Control

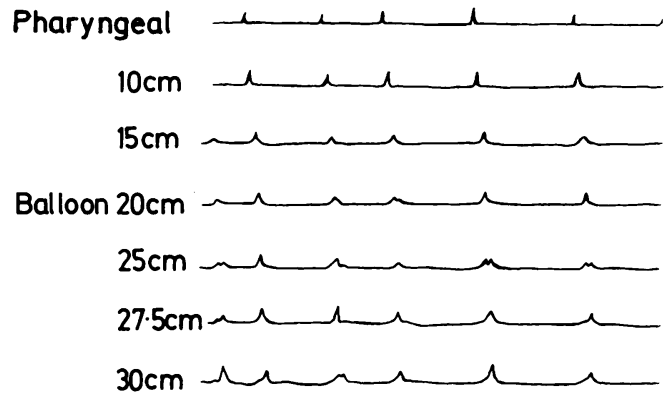

Distension

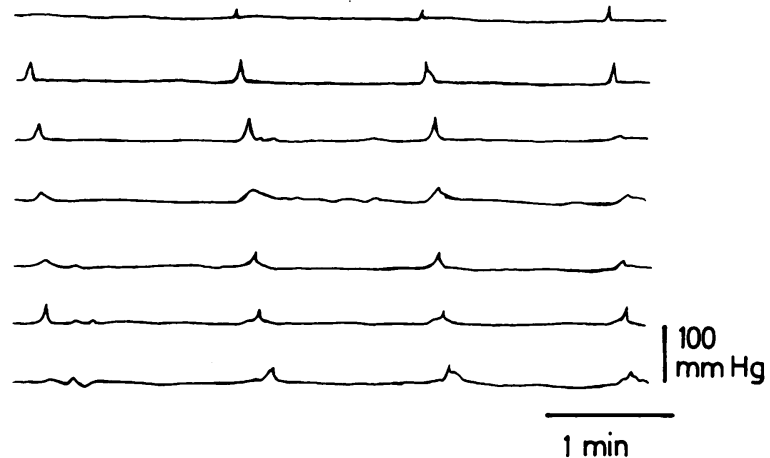

Fig. 4 Effect of oesophageal distension in a patient (no l) with normal standard manometry. During the control period normal peristalsis is seen. In contrast with Figure 2 there is neither a proximal increase in secondary activity nor a distal inhibition of primary peristalsis during distension.

the site of distension, and no persistent aborally directed traction on the balloon was experienced, though it was noted to coincide with swallowing. In the other three cases (case numbers 5, 7, and 9) a normal proximal response to distension was observed though one case (case number 7) showed no distal motor inhibition.

\section{Discussion}

Our results show that balloon distension of the normal human oesophagus induces a specific motor response, characterised by increased secondary motor activity above, and reduced motor activity below, the distension together with a strong aborally directed propulsive force. The term secondary contractile activity, rather than secondary peristalsis, has been used to describe this response because the activity observed by us differs from that previously described as secondary peristalsis. . $^{(1)}$ Experimentally induced secondary peristalsis usually refers to distally propagating motor activity induced by deflation rather than that seen during distension. This may in time prove to be an unnecessary distinction but has been made to avoid possible confusion until the exact nature of this motor activity and its relationship to previous studies has been better defined.

Other workers have studied the motor responses of the human oesophagus to distension, ${ }^{1-\infty}$ but the results have been variable possibly because of differ-

\section{Control}

\section{Pharyngeal}

$10 \mathrm{~cm}$

$15 \mathrm{~cm}$

Balloon $20 \mathrm{~cm}$

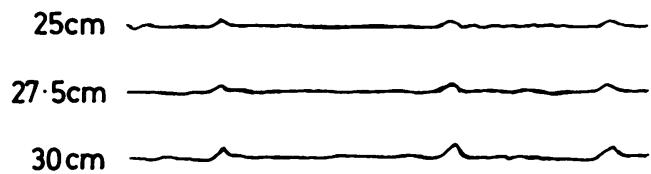

Distension

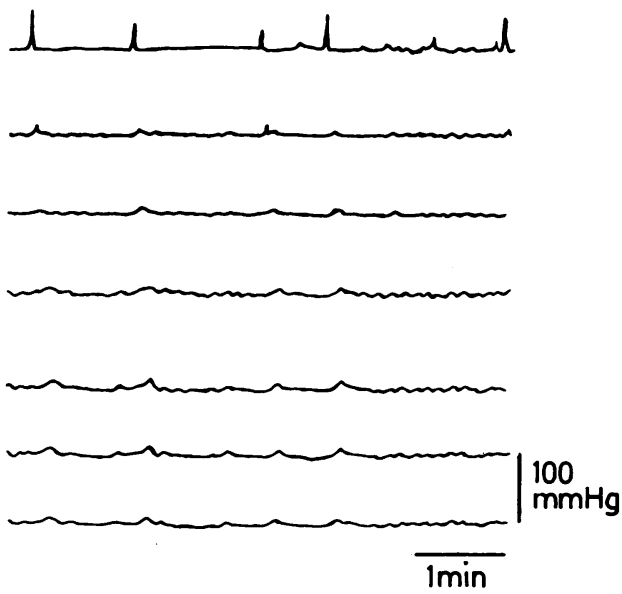

Fig. 5 Effect of oesophageal distension in a patient (no 6) with oesophageal hypomotility is shown. Poor primary peristalsis is seen during both control and distension periods, secondary contractile activity did not increase during distension. 

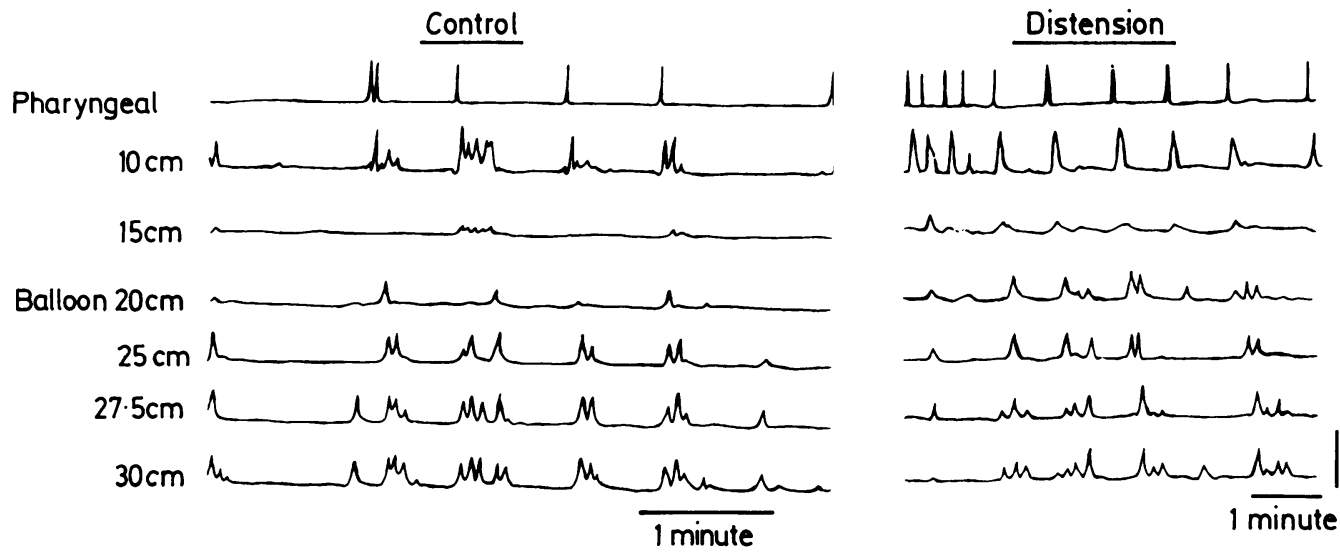

Fig. 6 Effect of oesophageal distension in patient (no 7) with oesophageal hypermotility is shown. Primary peristalsis is abnormal in both the control and distension periods, with multiple peaked contractions present in the distal oesophagus. No increase in proximal secondary contractile activity is seen during distension.

ences in the experimental protocols. Some workers have observed proximal motor excitation together with distal inhibition" ${ }^{\text {" }}$ but others? recognised no consistent pattern of motor activity even though an aboral force was noted. These findings contrast with our normal studies where proximal excitation was consistently seen. Such differences result from the type of distension used. We used a sensory end point to define adequate distension while others have used predetermined volumes, which may have produced more variable distension.

Motor responses to oesophageal distension have also been studied, both in vivo and in vitro, in animals." 14 Similar motor responses have been recorded under both experimental conditions indicating that the mechanisms for producing such motor activity are intrinsically mediated, though these responses can be modified through the vagus nerve." Three motor responses of the opposum oesophagus in response to distension have been described. ${ }^{111+}$ On balloon inflation there was a myogenically mediated response, the 'on response', during distension a cholinergically mediated contraction of the proximal longtitudinal muscle, the 'duration response' and on balloon deflation a distally propagating contractile wave starting just above the level of the distension, the 'off response'. The 'off response' appears to be mediated via non-adrenergic non-cholinergic nerves and is manometrically similar to secondary peristalsis. It is likely that the activity observed in our studies is the same as the "duration response' because of the temporal association with the distension and neuropharmacological similarily of the activities. The nature of the distal inhibition has not been defined in our studies but is probably mediated through a nonadrenergic non-cholinergic pathway, similar to that responsible for lower oesophageal sphincter relaxation. ${ }^{15}$

The different stimulation thresholds required for the proximal and distal responses also seem of interest. The proximal increase in activity was consistently initiated at a level of distension below that required for its perception. The distal inhibition, in contrast, did not occur until greater degrees of distension were induced and discomfort was felt. The proximal excitation may therefore be the more usual mechanism for clearing retained luminal contents which stimulate stretch receptors. The latter motor inhibition is probably not a mechanism for food transport under normal circumstances, although it might represent a subsidiary mechanism to encourage the clearance of larger boluses which would otherwise block the oesophagus.

Our patient studies appear to be the first to have applied intraluminal distension to the investigation of oesophageal transport problems and raise a number of issues for discussion. All the patients had severe chronic symptoms, which together with the prolonged oesophageal radionuclide transit, suggest that, in addition to inefficient primary peristalsis, the normal non-swallowing initiated mechanism for oesophageal clearance was impaired. The defective motor response to intraluminal distension in these people supports the idea of an abnormality of this secondary clearance mechanism. One group of patients (case numbers 3-5, 8, and 9) seem to belong to the spectrum of achalasia/diffuse oesophageal spasm $^{\text {1: }}$ as they show features of abnormal lower oesophageal sphincter relaxation or multipeaked primary peristaltic waves or both. A diffuse abnormality of the intrinsic oesophageal nerves is well recognised in achalasia ${ }^{1617}$ and presumably a similar 
abnormality occurs in diffuse oesophageal spasm, although data in such disorders seem lacking.

A further group (case numbers 1-3) had normal standard manometry but a prolonged isotope transit. Abnormal clearance in the presence of normal primary peristalsis has been recognised by other workers ${ }^{3}$ but why this should occur has not been resolved. Studies comparing the amplitude of oesophageal contraction with the force acting on a bolus have shown the two are not related ${ }^{18}$ so that contractions sufficient to produce normally appearing peristaltic waves during oesophageal manometry are not necessarily sufficient to ensure adequate oesophageal transport. It is important to note that all three cases failed to show any abnormality of oesophageal function except prolonged supine transit and an abnormal distension response, so that standard manometry alone would have failed to recognise any abnormality. These patients presumably suffer from a defective intrinsically mediated oesophageal clearance response.

Patient number 6 had low pressure primary peristaltic activity. Though such activity makes interpretation of the distension response difficult, failure to initiate any proximal motor excitation again suggests an intrinsic neural abnormality to be present.

Finally, two of the patients (case numbers 5 and 9) showed delayed transit with normal distension responses. A possible reason for the lack of abnormality in these patients is that the distension technique used was too crude to show a more subtle peristaltic impairment. Studies using graded submaximal stimulation, at levels of intraluminal distension, more likely to occur after food ingestion, might have identified abnormalities in such patients.

In conclusion, it appears that investigation of the oesophageal motor responses to distension could be a useful adjunct to standard oesophageal manometry in the investigation of patients with suspected oesophageal clearance disorders, particularly when standard manometry is normal. Distension is simple to do, increases the duration of oesophageal manometry by only a few minutes and seems to provide useful information about oesophageal motility which cannot otherwise be obtained. Further studies of these responses, in patients with both structural and functional oesophageal dysfunction using graded submaximal distension are required so that the specificity and diagnostic potential of this technique can be more fully evaluated.

Dr Kendall is a WEG Knott Research Fellow of the British Digestive Foundation. Dr Thompson is a Wellcome Trust Senior Lecturer in Medicine.
We would like to thank Professor Lennard-Jones for help in preparing this manuscript and Miss E Walker for assistance in the studies.

\section{References}

1 Goyal RK, Cobb BW. Motility of the pharynx, esophagus and esophageal sphincters. In: Lconard R Johnson, ed. Physiology of the gastrointestinal tract. New York: Raven Press, 1981: 359-91.

2 Blackwell JN, Hannan WJ, Adam RD, Heading RC. Radionuclide transit studies in the detection of oesophageal dysmotility. Gut 1983; 24: 421-6.

3 Russell COH, Hill LD, Holmes ER III, Hull DA, Gannon R, Pope CE II. Radionuclide transit: a sensitive screening test for esophageal dysfunction. Gastroenterology 1981; 80: 887-92.

4 Channer KS. Oesophageal abnormalities in patients with chest pain. Lancet 1986; i: 42-3.

5 Henderson RD. Esophageal manometry in clinical investigation. New York: Praeger Publishers, 1983.

6 Creamer B, Schlegel J. Motor responses of the esophagus to distension. J Appl Physiol 1957; 10: 498-504.

7 Winship DH, Zboralske FF. The esophageal propulsive force: Esophageal response to acute distension. J Clin Invest 1967; 46: 1391-401.

8 Fleshler B, Hendrix TR, Kramer P, Ingelfinger FJ. The characteristics and similarities of primary and secondary peristalsis in the esophagus. J Clin Invest 1959; 38: 110-6.

9 Hwang K. Mechanism of transportation of the content of the esophagus. J Appl Physiol 1954; 6: 781-96.

10 Christensen J, Lund GF. Esophageal responses to distension and electrical stimulation. J Clin Invest 1969; 48: $408-19$.

11 Arndorfer RC, Stef JJ, Dodds WJ, Linehạn JH, Hogan WJ. Improved infusion system for intraluminal esophageal manometry. Gastroenterology 1977; 73: 23-7.

12 Armitage P. Statistical methods in medical research. Oxford: Blackwell Scientific Publications, 1971.

13 DiMarino AJ, Cohen S. Characteristics of lower esophageal sphincter function in symptomatic diffuse esophageal spasm. Gastroenterology 1974; 66: 1-6.

14 Christensen J. Patterns and origins of some esophageal responses to stretch and electrical stimulation. Gastroenterology 1970; 59: 909-16.

15 Goyal RK, Ratten S. Nature of the vagal inhibitory innervation to the lower esophageal sphincter. J Clin Invest 1975; 55: 1119-26.

16 Smith B. The neurological lesion in achalasia of the cardia. Gut 1970; 11: 388-91.

17 Qualman SJ, Haupt HM, Yang P, Hamilton SR. Esophageal Lewy bodies associated with ganglion cell loss in achalasia: Similarity to Parkinson's disease. Gastroenterology 1984; 87: 848-56.

18 Schoen HJ, Morris DW, Cohen S. Esophageal peristaltic force in man, response to mechanical and pharmacological alterations. Am J Dig Dis 1977; 22: 589-97. 